\section{POS1381 BIOLOGIC TREATMENT OF ADULT-ONSET STILL'S DISEASE: A SINGLE CENTER EXPERIENCE}

B. Yurttas ${ }^{1}$, B. Egeli ${ }^{2}$, G. Guzelant Ozkose ${ }^{1}$, S. Ugurlu ${ }^{1} .{ }^{1}$ Istanbul UniversityCerrahpasa, Rheumatology, Istanbul, Turkey; ${ }^{2}$ Boston Children's Hospital, Immunology, Boston, United States of America

Background: Even though corticosteroids and cDMARDs are effective for inducing remission in patients with Adult-Onset Still Disease (AOSD), relapse is common. Hence, maintaining the clinical stability is challenging. Almost all of the patients face side effects because of high dose steroid treatment. Biological DMARDs have been reported to be effective in refractory patients.

Objectives: We aimed to evaluate the patients' outcomes who were diagnosed with AOSD and treated with at least one bDMARDs in our tertiary center.

Methods: Patients with AOSD who were followed in our clinic between 2007 and 2020 were screened retrospectively. For the diagnosis of AOSD, all of the patients fulfilled Yamaguchi criteria. The demographic characteristics, baseline and post-treatment clinical findings and outcomes were reported.

Results: Twenty-eight patients (21 F, $7 \mathrm{M})$ were screened (Figure 1). The mean disease duration of the first bDMARD was 21,76 $\pm 28,05$ months (mean $\pm S D$ ). The mean duration of bDMARD treatment was $37,04 \pm 30,75$ months. The reasons for starting a bDMARD were systemic symptoms (\%80) and chronic arthritis (\%20). All of the patients used methotrexate (MTX) except one. This patient had macrophage activation syndrome during diagnosis and was treated with cyclosporine. All of the patients were treated with corticosteroids $(34,28$ $\pm 26,70 \mathrm{mg} / \mathrm{d}$ ) and a cDMARD at initiation (22 of them MTX, 1 of them azathioprine, 2 of them cyclosporine and 1 of them IVIg). Anakinra was the most preferred biologic as a first-line treatment modality (TNF inhibitors $=5$, tocilizumab=4). The main reason for switching was loss of efficacy (8/22). Tocilizumab was the most used agent in $2^{\text {nd }}$ line and canakinumab was in $3^{\text {rd }}$ line. Twenty-two patients were in remission at last visit. Also, 15 patients were steroid-free, 14 patients were MTX-free. Patient global visual analogue scale, acute phase reactants and daily steroid dose were reduced significantly at last visit compared to the initial visit (Table 1).

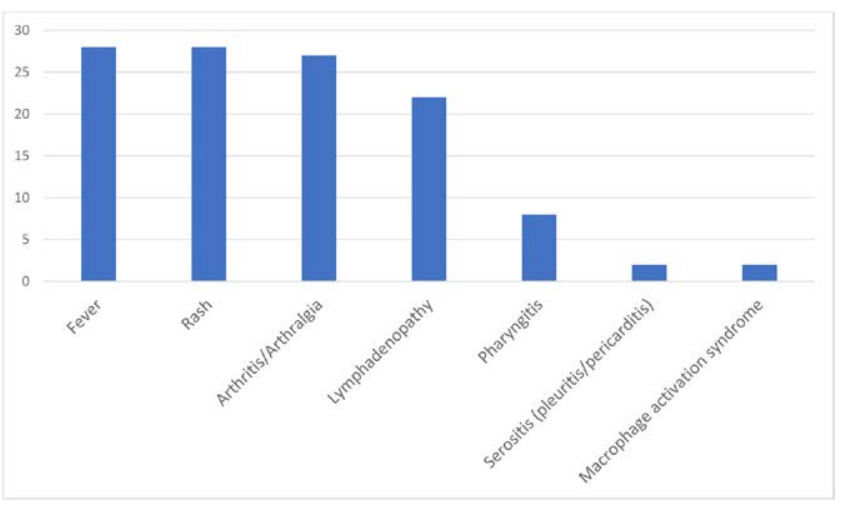

Figure 1. Presenting signs and the symptoms of the patients

Table 1. Comparison of important laboratory findings and the mean steroid dose

\begin{tabular}{lll}
\hline Clinical finding & $\begin{array}{l}\text { At initiation of bDMARD } \\
\text { mean } \pm \text { SD }\end{array}$ & $\begin{array}{l}\text { At the last visit } \\
\text { mean } \pm \text { SD }\end{array}$ \\
\hline PG-VAS & $9.8 \pm 0.8$ & $2.3 \pm 2.3$ \\
ESR $(\mathrm{mm} / \mathrm{h})$ & $34,28 \pm 33,95$ & $18.82 \pm 11.60$ \\
CRP $(\mathrm{mg} / \mathrm{l})$ & $70,76 \pm 67,80$ & $13.44 \pm 27.33$ \\
Ferritin $(\mathrm{ng} / \mathrm{mL})$ & $1662 \pm 1239$ & $275.7 \pm 381.4$ \\
Daily steroid dose (prednisolone, $\mathrm{mg} / \mathrm{d})$ & $34.28 \pm 26.70$ & $5.60 \pm 8.60$ \\
\hline
\end{tabular}

bDMARD treatment was terminated in 5 patients due to complete remission $(n=2)$ and side effects ( 1 of them pneumonia, 1 of them EBER $(+)$ Hodgkin Lymphoma and 1 of them tuberculosis). Six patients experienced local injection site reaction, none of them stopped treatment. Also, one patient died while she was in remission under anakinra treatment with an unknown cause.

Conclusion: The most common presenting symptoms in our cohort were fever and salmon-colored rash. Tocilizumab is an alternative treatment modality in cases with chronic arthritis and IL-1 inhibitors are an alternative for systemic course of disease. bDMARDs, especially IL-1 inhibitors are highly effective for refractory patients with AOSD.

Disclosure of Interests: None declared

DOI: 10.1136/annrheumdis-2021-eular.3968

\section{\begin{tabular}{|l|l}
\hline POS1382 RITUXIMAB FOR INDUCTION OF REMISSION IN TYPE \\
\hline
\end{tabular} 1 AUTOIMMUNE PANCREATITIS: A SYSTEMATIC REVIEW AND META-ANALYSIS}

M. Lanzillotta ${ }^{1}$, G. Capurso ${ }^{2}$, Z. Wallace ${ }^{3}$, O. Karadag ${ }^{4}$, L. Dagna5, E. Della Torre5. 'San Raffaele Scientific Institute, Unit of Immunology, Rheumatology, Allergy and Rare Diseases, Milan, Italy; ${ }^{2}$ San Raffaele Scientific Institute, PancreatoBiliary Endoscopy and EUS Division, Milan, Italy; ${ }^{3}$ Massachusetts General Hospital, Clinical Epidemiology Unit, Division of Rheumatology, Allergy, and Immunology, Boston, United States of America; ${ }^{4}$ Hacettepe University, Faculty of Medicine, Department of Internal Medicine, Division of Rheumatology, Ankara, Turkey; ${ }^{1}$ San Raffaele Scientific Institute, Unit of Immunology, Rheumatology, Allergy and Rare Diseases, Milan, Italy

Background: Type I autoimmune pancreatitis (AIP) is a rare form of pancreatitis that belongs to the IgG4-related disease (IgG4-RD) spectrum (1). Autoimmune pancreatitis responds brilliantly to glucocorticoids, but iatrogenic toxicity associated with prolonged steroid therapy represents a relevant clinical concern in the long-term (2). B cell depletion therapy proved to be effective in inducing IgG4-RD remission, yet most evidence are derived from small and heterogenous cohorts. Objectives: We performed a systematic review and meta-analysis to estimate the remission rate following rituximab-based induction treatment.

Methods: Two reviewers searched MEDLINE, SCOPUS, and EMBASE until December 2020 to identify studies on remission rate and relapse rate of Type I AIP after induction of remission with rituximab. Studies involving three or more patients were included, including the most recent or most numerous cohorts in case of duplicates This study was conducted in accordance with Preferred Reporting Items for Systematic Reviews and Meta-Analyses guidelines. Pooled effects were calculated using a random-effects model and expressed in terms of pooled remission, relapse and adverse effects (AEs) rates.

Results: Seven cohort studies met inclusion criteria for the meta-analysis for a total of 101 patients. Reasons for rituximab administration were relapsing disease $(63.5 \%)$, new diagnosis (18.5\%) or glucorticoids intolerance $(17.9 \%)$. The median follow-up time was 18.5 months. The pooled rate of complete response at 6 months from induction of remission was $88.9 \%$ (95\% Cl $80.5 \%-93.9 \%)$ without heterogeneity $\left(I^{2}=0 \%\right)$ (Figure 1). The median time to relapse was 9.75 months. The pooled estimate of relapse rate was $21 \%(95 \% \mathrm{Cl} 10.5 \%-40.3 \%)$ with moderate heterogeneity $\left(I^{2}=51 \%\right)$, being $35.9 \%(95 \% \mathrm{Cl} 17.3 \%-60.1 \%)$ in the 4 studies with rate of other organs involvement $(\mathrm{OOI})>80 \%$ and as low as $10.1 \%(4.8 \%-20.3 \%)$ in the others. The pooled estimate of rituximab-related AEs was $25 \%(95 \% \mathrm{Cl} 8.8 \% 53 \%)$ with substantial heterogeneity $\left(I^{2}=73.6 \%\right)$. There was no publication bias.

Conclusion: Treatment of type I AIP with rituximab is associated with high remission rate, a higher relapse rate in presence of $\mathrm{OOI}$ and limited AEs. Randomized controlled trials with adequate power are needed to confirm these findings.

\section{REFERENCES:}

[1] Lanzillotta M, Mancuso G, Della-Torre E. Advances in the diagnosis and management of IgG4 related disease. BMJ. 2020;369:m1067

[2] Lanzillotta M, Vinge-Holmquist O, Overbeek KA, et al. PrescrAIP: A Pan-European Study on Current Treatment Regimens of Auto-Immune Pancreatitis. Front Med (Lausanne). 2020;7:408

Fig.1 Pooled rate of complete response

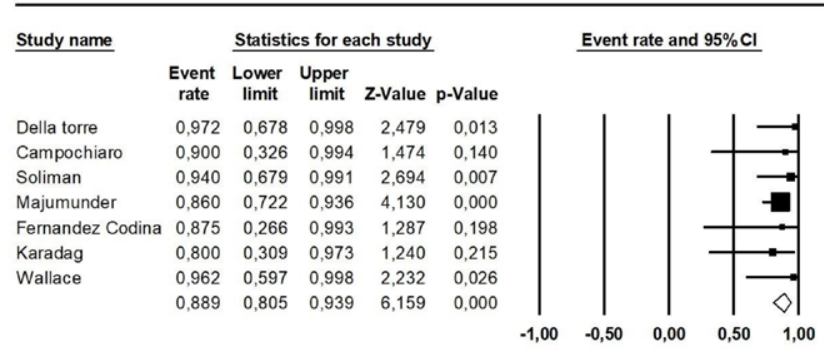

$88.9 \%$

Meta Analysis

Disclosure of Interests: None declared

DOI: 10.1136/annrheumdis-2021-eular.3993

\section{POS1383 THE ASSOCIATION BETWEEN BARIATRIC SURGERY AND DUPUYTREN DISEASE: A COHORT STUDY FROM SWEDISH NATIONWIDE HEALTHCARE REGISTRIES}

T. Burkard ${ }^{1}$, J. Lane ${ }^{2}$, D. Holmberg ${ }^{3}$, A. M. Burden ${ }^{1,4}$, D. Furniss ${ }^{2} .{ }^{1}$ ETH Zurich, Department of Chemistry and Applied Biosciences, Zurich, Switzerland;

${ }^{2}$ University of Oxford, Nuffield Department of Orthopaedics, Rheumatology, and 